\title{
Author Correction: Liquid flow reversibly creates a macroscopic surface charge gradient
}

\author{
Patrick Ober (1D, Willem Q. Boon (1), Marjolein Dijkstra (D), Ellen H. G. Backus (1D, René van Roij (1) \& Mischa Bonn (D)
}

Correction to: Nature Communications https://doi.org/10.1038/s41467-021-24270-x, published online 2 July 2021.

The original version of this Article contained an error in Equation 8.

The second line of this equation omitted the multiplication factor 4 in the second term, and incorrectly read:

$$
\frac{\bar{\rho}_{\mathrm{F}}(x)}{\rho_{\mathrm{F}, \mathrm{b}}}=\left\{\begin{array}{cl}
1+\Delta \rho_{\mathrm{F}}\left(1-\frac{x^{2}}{L^{2}}\right) & \text { if } \mathrm{Pe} \ll 1 ; \\
1+\frac{\Delta \rho_{\mathrm{F}}}{\mathrm{Pe}}\left(1+\frac{x}{L}\right) & \text { if } \mathrm{Pe} \gg 1
\end{array}\right. \text {. }
$$

The correct form of Equation 8 is:

$$
\frac{\bar{\rho}_{\mathrm{F}}(x)}{\rho_{\mathrm{F}, \mathrm{b}}}=\left\{\begin{array}{ll}
1+\Delta \rho_{\mathrm{F}}\left(1-\frac{x^{2}}{L^{2}}\right) & \text { if } \mathrm{Pe} \ll 1 ; \\
1+4 \frac{\Delta \rho_{\mathrm{F}}}{\mathrm{Pe}}\left(1+\frac{x}{L}\right) & \text { if } \mathrm{Pe} \gg 1
\end{array} .\right.
$$

This has been corrected in the PDF and HTML versions of the Article.

The original version of the Supplementary Information associated with this Article contained an error in Supplementary Equation 17.

The equation omitted a factor $1 / 2$ in front of the Peclet number Pe, and incorrectly read:

$$
\frac{\rho(x)}{\rho_{\mathrm{b}}}=1+\frac{\Delta \rho_{\max }}{\mathrm{Pe}}\left(\frac{2 x}{L}+\left(1+e^{2 \mathrm{Pe}}-2 e^{\mathrm{Pe}\left(1+\frac{x}{L}\right)}\right)(\operatorname{Coth}(\mathrm{Pe})-1)\right)
$$

The correct form of Supplementary Equation 17 is:

$$
\frac{\rho(x)}{\rho_{\mathrm{b}}}=1+2 \frac{\Delta \rho_{\max }}{\mathrm{Pe}}\left(\frac{2 x}{L}+\left(1+e^{\mathrm{Pe}}-2 e^{\frac{\mathrm{Pe}}{2}\left(1+\frac{x}{L}\right)}\right)\left(\operatorname{Coth}\left(\frac{\mathrm{Pe}}{2}\right)-1\right)\right)
$$

The original version of the Supplementary Information associated with this Article also contained an error in the $14^{\text {th }}$ sentence of the $6^{\text {th }}$ paragraph of Supplementary Discussion 2, where the Peclet number was incorrectly defined as Pe $=2 u L / D$. The correct version states $\mathrm{Pe}=2 \bar{u} L / D$ in place of $\mathrm{Pe}=2 u L / D$.

The HTML has been updated to include a corrected version of the Supplementary Information.

Published online: 24 November 2021

\section{Additional information}

Supplementary information The online version contains supplementary material available at https://doi.org/10.1038/s41467-021-27209-4. 
(c) Open Access This article is licensed under a Creative Commons Attribution 4.0 International License, which permits use, sharing, adaptation, distribution and reproduction in any medium or format, as long as you give appropriate credit to the original author(s) and the source, provide a link to the Creative Commons license, and indicate if changes were made. The images or other third party material in this article are included in the article's Creative Commons license, unless indicated otherwise in a credit line to the material. If material is not included in the article's Creative Commons license and your intended use is not permitted by statutory regulation or exceeds the permitted use, you will need to obtain permission directly from the copyright holder. To view a copy of this license, visit http://creativecommons.org/licenses/by/4.0/.

(C) The Author(s) 2021 